\title{
KALİKSAREN TÜREVI İMMOBİLİZE EDİLMİŞ MERRIFIELD REÇİNESİ İLE KAPLI QCM SENSÖRÜNDE SULU ORTAMDA p-NITROFENOL ALGILANMASI
}

\author{
${ }^{1}$ Egemen ÖZÇELIKK, ${ }^{2}$ Farabi TEMEL, ${ }^{3}$ Mustafa TABAKCI \\ 1,2,3Konya Teknik Üniversitesi, Mühendislik ve Doğa Bilimleri Fakültesi, Kimya Mühendisliği Bölümü, Konya, \\ TÜRKIYE \\ 19egemen.ozcelik@gmail.com, 2ftemel@ktun.edu.tr, ${ }^{3}$ mtabakci@ktun.edu.tr
}

(Geliş/Received:19.01.2019; Kabul/Accepted in Revised Form:27.02.2019)

ÖZ: Bu çalışma, kaliksaren hidrazin amit türevi içeren Merrifield reçinesi (KIMR) ile modifiye edilmiş bir QCM sensörün sulu ortamdaki $p$-nitrofenol (PNF) için algılama çalışmalarını açıklamaktadır. Bu amaçla öncelikle KIMR hazırlanarak yapısı karakterize edildi ve daha sonra QCM kristal yüzeyine kaplandı. Elde edilen KIMR modifiyeli sensörün PNF algılama çalışmaları, PNF için iyi bir algılama gösterdiğini ortaya çıkardı. Böylece sulu ortamda farklı konsantrasyon ve farklı $\mathrm{pH}^{\prime}$ larda algılama çalışmaları gerçekleştirildi. Sonuçlardan limit algılama değerinin $0,34 \mathrm{mM}$ olduğu ve en iyi algılamanın $\mathrm{pH} 10 \mathrm{da}$ gerçekleştiği anlaşıldı. Ayrıca Langmuir ve Freundlich adsorpsiyon izotermlerinden KIMR'nin adsorpsiyon kapasitesi, $372 \mathrm{mg} / \mathrm{g}$ olarak hesaplandi.

Anahtar Kelimeler: Adsorption, Kaliksaren, Kuartz kristal mikrobalans, p-Nitrofenol, Sensör

\section{Sensing of p-Nitrophenol in Aqueous Media on QCM Sensor Coated with Calixarene Derivative Immobilized Merrifield Resin}

\begin{abstract}
This study describes the sensing studies of QCM sensor which modified with calixarene hydrazine amide derivative immobilized Merrifield resin (CIMR) for the $p$-nitrophenol (PNP) sensing in aqueous media. For this aim, first CIMR was prepared and its structure was characterized, and then it was coated onto the QCM crystal surface. The PNP sensing studies of CIMR modified QCM sensor revealed good results for PNP sensing. Thus, it was performed the sensing studies at different concentration and $\mathrm{pHs}$ in aqueous media. From the results, it was found that the limit of detection was $0.34 \mathrm{mM}$ and optimum $\mathrm{pH}$ value was 10 for PNF sensing by CIMR modified QCM sensor. Moreover, it was calculated the adsorption capacity of CIMR as $372 \mathrm{mg} / \mathrm{g}$ from the Langmuir and Freundlich isotherm models.
\end{abstract}

Key Words: Adsorption, Calixarene, Quartz Crystal Microbalance, p-Nitrophenol, Sensor

\section{GİRIŞ (INTRODUCTION)}

Endüstrinin gelişmesi birçok avantajı beraberinde getirirken, bunun yanında kirlilik oluşturması gibi dezavantajlara da sahiptir. Organik kirleticilerin varlığı ve toksik etkileri, yüzey ve yer altı sularının kirlenmesinde, bitki, hayvan ve insan hayatını etkileyecek düzeyde kirlilik kaynağı oluşturmaktadır. Organik kirleticiler arasında; fenolik malzemeler ve türevleri, atık sularda bulunan kirleticilerden önemli kirleticilerdir. $\mathrm{Bu}$ malzemeler, farmasötik, petrokimya ve kimyasal üretim proseslerinde kullanılmaktadırlar. Fenolik hidrokarbonların oluşturduğu kirliliğin giderilmesi için farklı metotlar geliştirilmiştir. Bu amaçla, kimyasal oksidasyon, ekstraksiyon, adsorpsiyon gibi giderme yöntemleri kullanılmıştır (Lai ve diğ, 2014; Yu ve diğ, 2010; Dolaksız ve diğ, 2017).

Atık sularda kirliliği gidermeden önce, kirliliğin hangi boyutlarda olduğunu belirlemek için kantitatif analiz yapılması gerekmektedir. Bu amaçla sensör teknolojilerinin kullanımı ön plana 
çıkmaktadır. Bilinen sensör teknolojileri arasında, Kuartz Kristal Mikrobalans (Quartz Crystal Microbalance - QCM) teknolojisi, kütle hassasiyeti olan piezoelektrik temelli bir sensör çeşididir. Nanogram seviyesinde algılamaya izin veren bu sensör teknolojisi, kristal yüzeyinde meydana gelen kütle değişimini Sauerbrey denklemi sayesinde (Sauerbrey, 1959) frekans değişimine dönüştürerek analiz yapılmasına izin verir.

QCM ölçüm tekniği, algılayıcı molekülün farklı analitlere karşı algılama özelliklerinin incelenmesinde kullanılan tekniklerden biridir. Adsorpsiyon işlemi, algılayıcı molekülün analit ile etkileşmesiyle yüzeyde meydana gelen frekans değişiminin belirlenmesi prensibine dayanır. Adsorpsiyon işlemine bağlı olarak meydana gelen kütle değişimi, moleküller arası veya molekül içi iyon-proton değişiminden kaynaklanabilmektedir.

Sensör uygulamalarında, algılayıcı moleküller olarak polimerler ve makromoleküller kullanılmaktadır. Bunlardan birisi de $p$-ter-bütilfenol ve formaldehitin bazik ortamda kondenzasyon reaksiyonu sonucunda oluşan halkalı yapıdaki "kaliksaren" molekülleridir. Türevlendirilebilme yeteneği sınırsız olan bu moleküller, farklı fonksiyonel gruplar ile türevlendirilerek host-guest etkileşimlerinin incelenebilmesine olanak tanımaktadırlar (Temel ve di ̆. , 2017).

$\mathrm{Bu}$ çalı̧̧mada ise hidrazinamit fonksiyonel grubu içeren bir kaliksaren türevi, Merrifield reçinesine immobilize edilerek polimerik bir yapı (KIMR) elde edilmiş ve bu yapı sulu ortamlarda $p$-nitrofenol (PNF) algılanması için sıvı temaslı QCM sisteminde algılayıcı yüzey olarak kullanılmıştır. Böylece önemli bir organik kirletici olan PNF'nin KIMR kaplanmış QCM yüzeyinde algılanma çalışmaları gerçekleştirilmiştir.

\section{MATERYAL VE YÖNTEM (MATERIAL AND METHOD)}

\section{Kimyasallar ve Cihazlar (Chemicals and Instrumentations)}

Sentezlenen moleküllerin erime noktasının belirlenmesi için Ez-Melt aparatı kullanıldı. Varian marka $400 \mathrm{MHz}$ NMR Spektrometresi, Perkin Elmer marka 100 FTIR spektrometresi ve Leco marka CHNS-932 Anaylzer Elementel Analiz cihazı ile sentezlenen yapılar karakterize edildi. Sentezler sırasında, Merck marka Kieselgel $60 \mathrm{~F}_{254}$ ince tabaka kromatografisi kullanılarak sentezler takip edildi. Çalışma sırasında kullanılan tüm malzemeler ve reaktifler analitik kalitede olup Merck ya da Sigma Aldrich firmasından tedarik edildi.

QCM sensör çalışmalarını gerçekleştirmek için Stanford Research System (California, ABD) marka QCM200 cihazı kullanıldı. QCM sisteminde $5 \mathrm{MHz}$ temel frekans değerine sahip altın elektrotlu kuvars kristaller kullanıldı. QCM kristallerinin temizlenmesi için, ISOLAB marka ultrasonik banyo kullanıldı. Tüm çalışmalar Labconco-5220120 glove box ünitesi içerisinde gerçekleştirildi.

\section{Algılayıcı Molekülün Sentezi ve Merrifield Reçinesine İmmobilizasyonu (Synthesis of Sensing Molecules and İmmobilization on Merrifield Resin)}

Algılayıcı malzeme olarak kullanılacak kaliks[4]aren türevi, literatürde belirtildiği gibi sentezlendi (Gutsche ve Iqbal, 1990; Collins ve diğ., 1991; Maity ve diğ, 2011). Sentezlenen algılayıcı molekülün Merrifield reçinesine immobilizasyonu için literatürdeki bilinen yöntem uygulanarak aşağıda verildi. Sentez şeması ise Şekil 1'de gösterildi. 

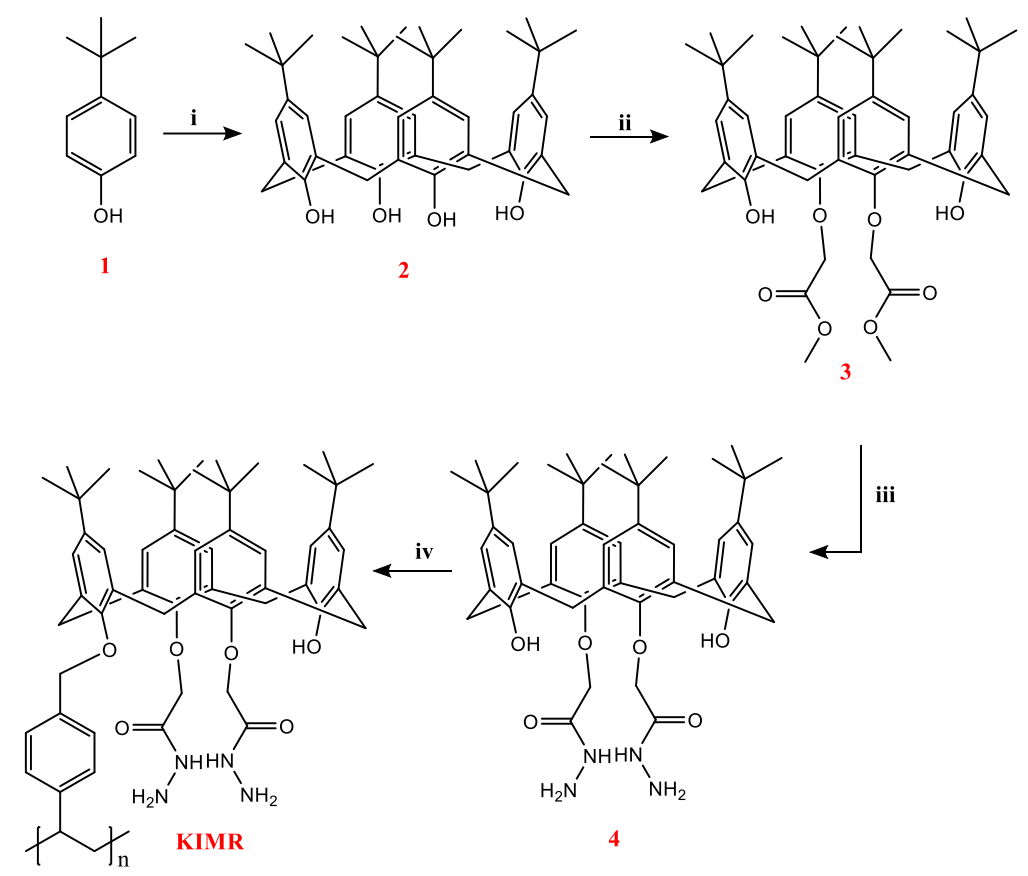

Şekil 1. Kaliksaren hidrazin amit türevinin sentez şeması ve Merrifield reçinesine immobilizasyonu (i) formaldehit, $\mathrm{NaOH}$, difenileter; (ii) metilbromoasetat, $\mathrm{K}_{2} \mathrm{CO}_{3}$, aseton; (iii) hidrazin hidrat, kloroformmetanol (1:3); (iv) Merrifield reçinesi, $\mathrm{NaI}, \mathrm{K}_{2} \mathrm{CO}_{3}$, kuru aseton

Figure 1. Synthesis of calixarene hydrazine amide derivative and its immobilization on Merrifield resin (i) formaldehyde, $\mathrm{NaOH}$, diphenyl ether; (ii) methylbromoacetate, $\mathrm{K}_{2} \mathrm{CO}_{3}$, acetone; (iii) hydrazine hydrate, chloroform-methanol (1:3); (iv) Merrifield resin, $\mathrm{NaI}_{2} \mathrm{~K}_{2} \mathrm{CO}_{3}$, dry acetone

Merrifield reçinesi $(0,0252 \mathrm{~g}, 0,0504 \mathrm{mmol})$, potasyum karbonat $(0,375 \mathrm{~g})$, sodyum iyodür $(0,75 \mathrm{~g})$, ve $0,4 \mathrm{~g} 4$ nolu bileşik $(0,504 \mathrm{mmol})$ kuru aseton $(50 \mathrm{~mL})$ içerisinde 48 saat boyunca geri soğutucu altında kaynatıldı. Süresi tamamlandıktan sonra karışım süzülür ve üzerinden aseton ile yıkandı, ardından çözücü vakum altında kuruluğa kadar uzaklaştırıldı. Diklorometan içerisinde çözülen katı madde, $\mathrm{HCl}$ ile ekstrakte edilip, asitliği giderildi. Organik faz ayrıldı, kurutuldu ve çözücüsü uzaklaştırılarak KIMR elde edildi. (Memon ve diğ, 2006). IR: $3316 \mathrm{~cm}^{-1}(\mathrm{~N}-\mathrm{H}), 1689 \mathrm{~cm}^{-1}$ (C=O), $1047 \mathrm{~cm}^{-1}$ (C-O).

\section{Modifiye QCM Sensörlerinin Hazırlanması (Preparation of Modified QCM Sensors)}

QCM kristallerinin yüzeyi modifiye edilmeden önce, kristaller ultrasonik banyo içerisinde kloroform ile yıkandı, saf su ve aseton ile yüzeyi temizlendi, ultra saf azot gazı ile kurutuldu. Temizlendikten sonra, QCM kristali modifiye edilmeden önce temel frekansı kaydedildi.

KIMR maddesinin 1,0 mM olacak şekilde kloroform içerisinde çözeltisi hazırlandı. Hazırlanan çözelti damlatma yöntemiyle QCM kristalinin yüzeyine damlatılarak, çözücünün uçması beklendi. Çözücüsü tamamen uzaklaştıktan sonra, frekans değeri kaydedilerek, kaplama öncesi ve sonrasındaki fark hesaplanarak kaplama miktarı belirlendi.

\section{$p$-Nitrofenol (PNF) Algılama Çalışmaları (Sensing Studies of $p$-Nitrophenol)}

Buradaki QCM sisteminin çalışma prensibi daha önceki çalışmada verilmiştir (Temel ve Tabakci, 2016). Çalışmalarda kullanılan sıvı temaslı ölçüm sistemi ise Şekil 2'de görülmektedir. Buna göre, öncelikle modifiye QCM kristalleri, QCM akış hücresine yerleştirildi. Ardından peristaltik pompa yardımı ile sistemden saf su geçirilerek sistemin kararlı hale gelmesi sağlandı. Daha sonra, PNP çözeltisi sisteme verildi ve gerçekleşen adsorpsiyon sonucundaki frekans değişimi kaydedildi. Adsorpsiyon 
tamamlandiktan sonra, sisteme yeniden saf su verildi ve bu kez de desorpsiyon sonucundaki frekans değerinin başlangıç değerine gelmesi beklendi.

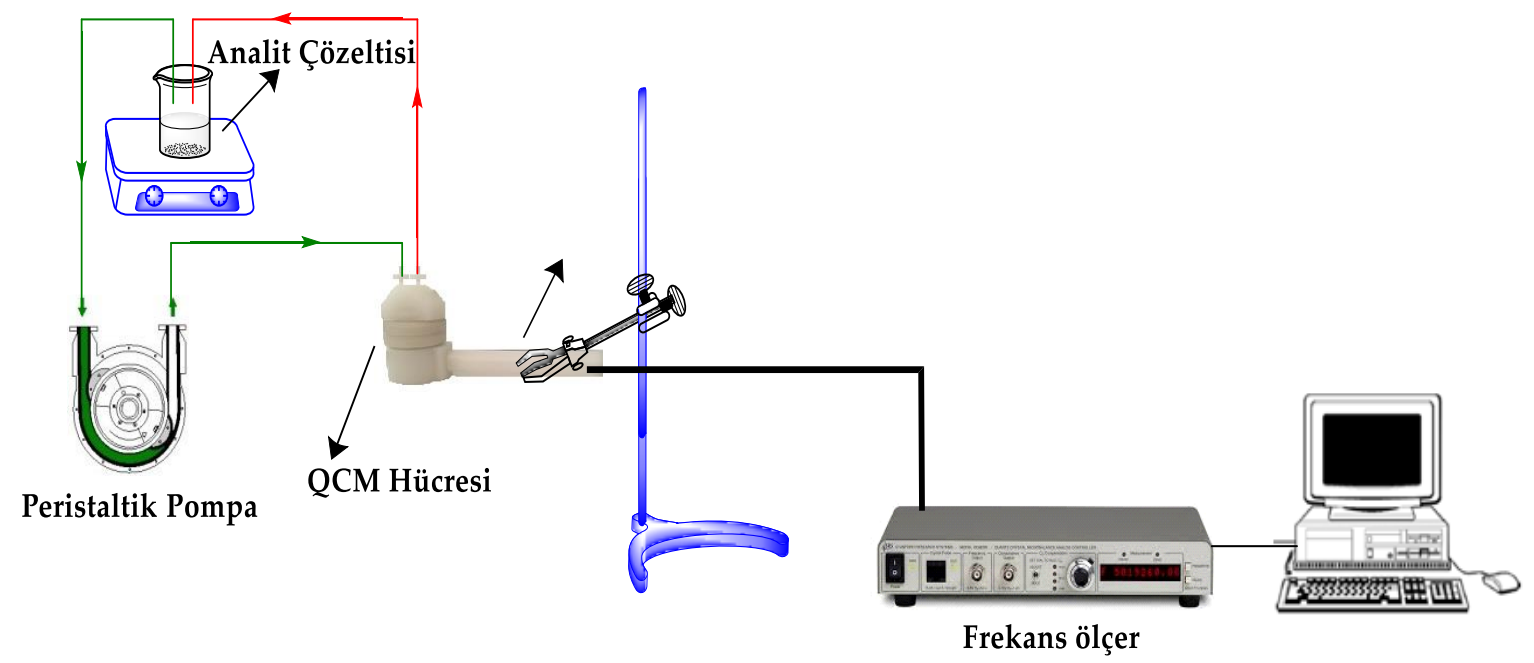

Şekil 2. Sıvı temaslı ölçüm sisteminin gösterimi

Figure 2. Presentation of liquid contact measuring system

\section{BULGULAR VE TARTIŞMA (RESULTS AND DISCUSSION)}

Sentez ve Karakterizasyon (Synthesis and Characterization)

Kaliksarenler, farklı analit molekülleri ile kompleks yapabilme özelliklerine sahip makrosiklik yapıdaki bileşiklerdir ve sensör çalışmalarında algılayıcı molekül olarak kullanılabilmektedirler. Sensör çalışmalarında, algılayıcı moleküller ile analit arasındaki etkileşim dolayısıyla gerçekleşen algılama ölçülerek malzemenin algılama özelliği belirlenmektedir (Temel, 2013). Bu çalışmada ise hedef algılayıcı moleküle ulaşmak için öncelikle $p$-ter-bütilkaliks[4]aren türevleri(1-4), literatür metoduna göre sentezlenmiş ve karakterizasyonları yapılmıştır (Gutsche ve Iqbal, 1990; Maity ve diğ, 2011; Memon ve diğ, 2006). Daha sonra 4 no'lu bileşiğin Merrifield reçinesi üzerine immobilizasyonu ile KIMR polimerik yapısı elde edilmiştir. Hazırlanan KIMR için FT-IR ile karakterizasyon işlemi yapılmış ve ilgili spektrum Şekil 3'te verilmiştir. Bilindiği gibi $698 \mathrm{~cm}^{-1}$ da görülen pik Merrifield yapısına ait olan C-Cl bağına aittir. Dolayısıyla KIMR'nin FT-IR spektrumu incelendiğinde Merrifield'a ait $698 \mathrm{~cm}^{-1}$ deki bu pikin kaybolduğu, C-O için $1047 \mathrm{~cm}^{-1}, \mathrm{C}=\mathrm{O}$ için $1689 \mathrm{~cm}^{-1}$ ve N-H için $3316 \mathrm{~cm}^{-1}$ piklerin oluştuğu görülmüştür. Böylece immbolizasyon işleminin gerçekleştiği doğrulanmıştır. 


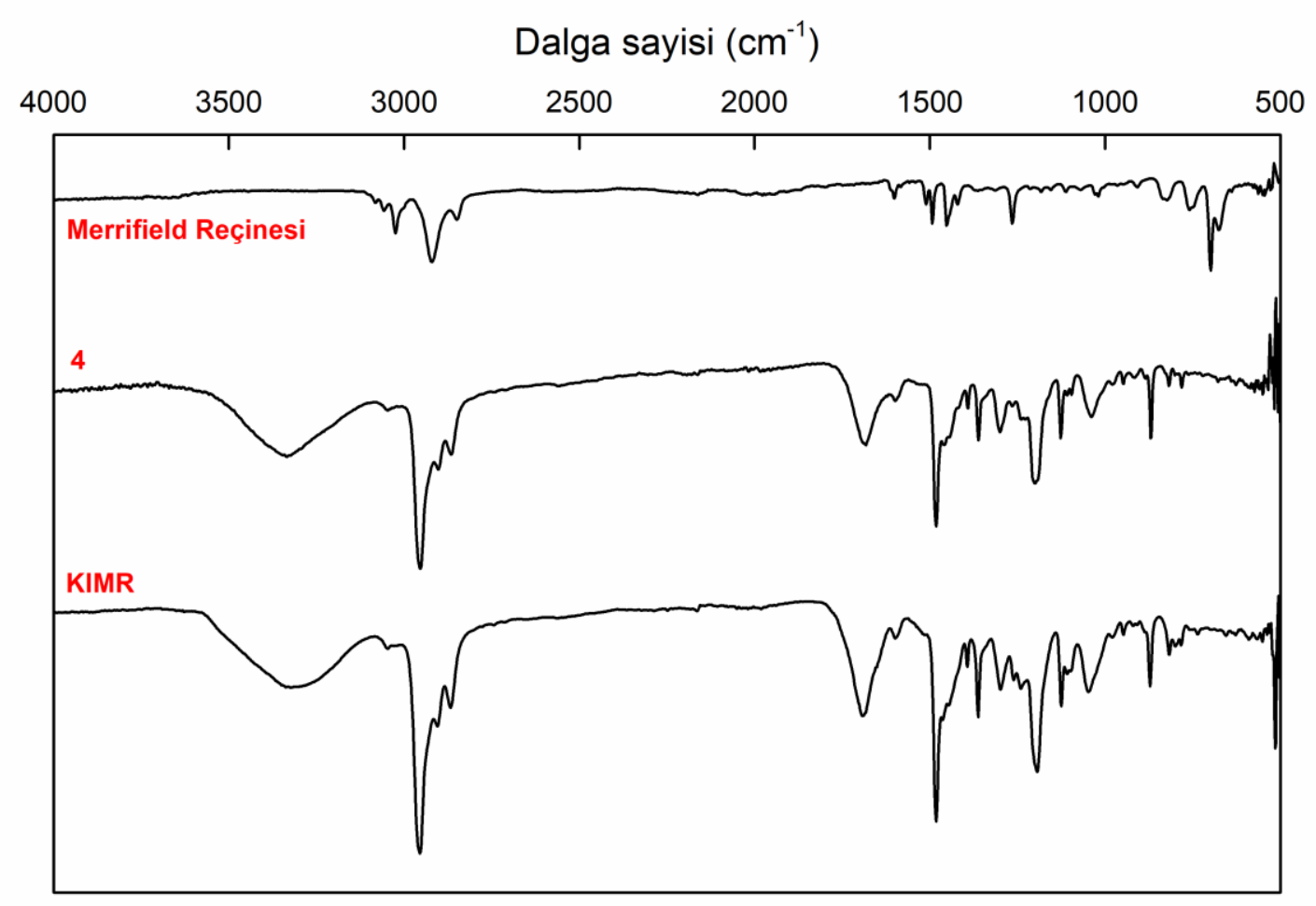

Şekil 3. Merrifield reçinesi, 4 no'lu bileşik ve KIMR için FTIR Spektrumları Figure 3. FTIR spectra for Merrifield resin, compound 4 and KIMR

\section{Modifiye QCM Kristallerinin Hazırlanması ve Sulu Ortam Algılama Çalışmaları}

Hazırlanan polimerik KIMR maddesi, QCM kristalleri yüzeyine damlatma metodu kullanılarak kaplanarak KIMR modifiyeli bir QCM sensör edilmiştir. QCM sensörün modifiye edilmeden önce ve sonraki frekans değerleri arasındaki fark ya da QCM kristali üzerindeki kaplamanın frekans değeri 780 $\mathrm{Hz}$ olarak hesaplanmıştır. KIMR modifiyeli QCM sensörü daha sonra Şekil 2'de gösterilen QCM sistemindeki akış hücresine yerleştirilerek sulu ortamda PNF algılama çalışmaları için kullanılmıştır.

\section{$p$-Nitrofenol algılama çalışması (Sensing studies of $p$-Nitrophenol)}

KIMR modifiyeli QCM sensörünün 10-2 M PNF çözeltisine karşı frekans değişimi, Şekil 4'te verilmiştir. Frekans değişimi incelendiğinde, PNF çözeltisini algılama sonrasında, adsorpsiyon sürecinin tamamlandıktan sonra, ortama saf su verilerek desorpsiyon işleminin gerçekleştiği ve bu sayede QCM sensörünün yüzeyinde analit kalmadığı ve bir sonraki çalışma için uygun olduğu görülmüştür. Bilindiği gibi bir sensörün, analit ve algılayıcı molekülleri arasındaki stokiyometrik oranı hesaplanabilmektedir. Stokiyometrik oran, bir mol algılayıcı molekülün kaç mol analit tuttuğunu belirlemek için kullanılan bir parametredir. Literatürde (Temel ve diğğ 2017) belirtildiği gibi hesaplanan stokiyometrik oran bu çalışma için 0,296 olarak bulunmuştur. 


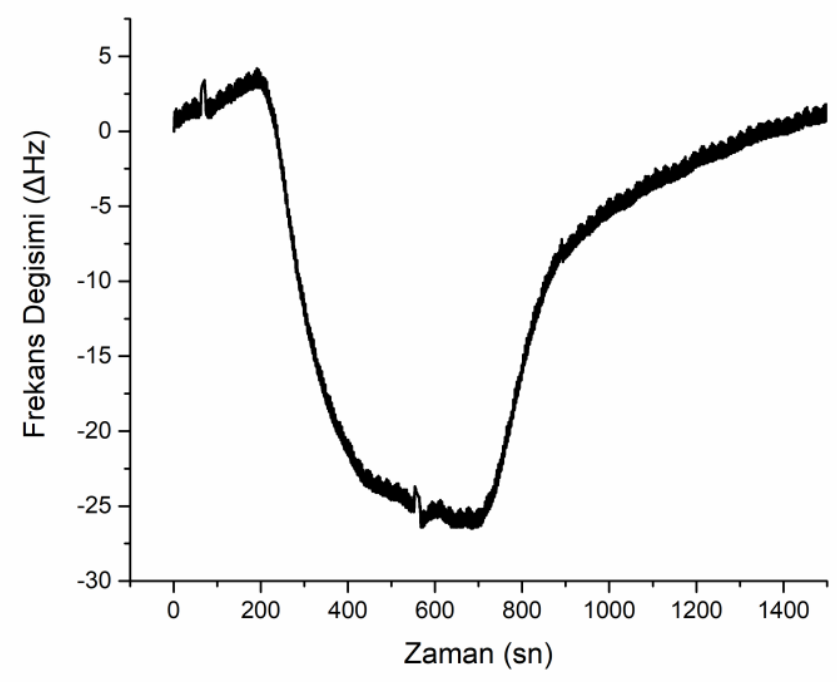

Şekil 4. PNF (10-2 M)'ye karşı KIMR modifiyeli QCM sensörünün frekans değişimi Figure 4. Frequency change of KIMR modified QCM sensor towards $10^{-2} M$ PNF

\section{Konsantrasyon çalışması (Concentration study)}

KIMR kaplı QCM sensörlerinin farklı konsantrasyondaki PNF çözeltilerine karşı sulu ortamda algılama çalışmaları da gerçekleştirilmiştir. Buna göre $10^{-3}-10^{-2} \mathrm{M}$ aralığındaki farklı PNF çözeltilerinin algılama sonucundaki frekans değişimi ve regresyon grafiği Şekil 5'te verilmiştir. Şekil 5 'teki sonuçlara göre, PNF çözeltisinin konsantrasyonu arttıkça sensör tepkisinin de giderek arttığı görülmüştür. Regresyon grafiğine göre, $R^{2}$ değeri 0,9996 olarak ortaya çıkmıştır. Limit algılama değeri ise literatürdeki gibi hesaplanarak (Temel ve di $\breve{g}$, 2017) 0,34 mM olarak bulunmuştur.

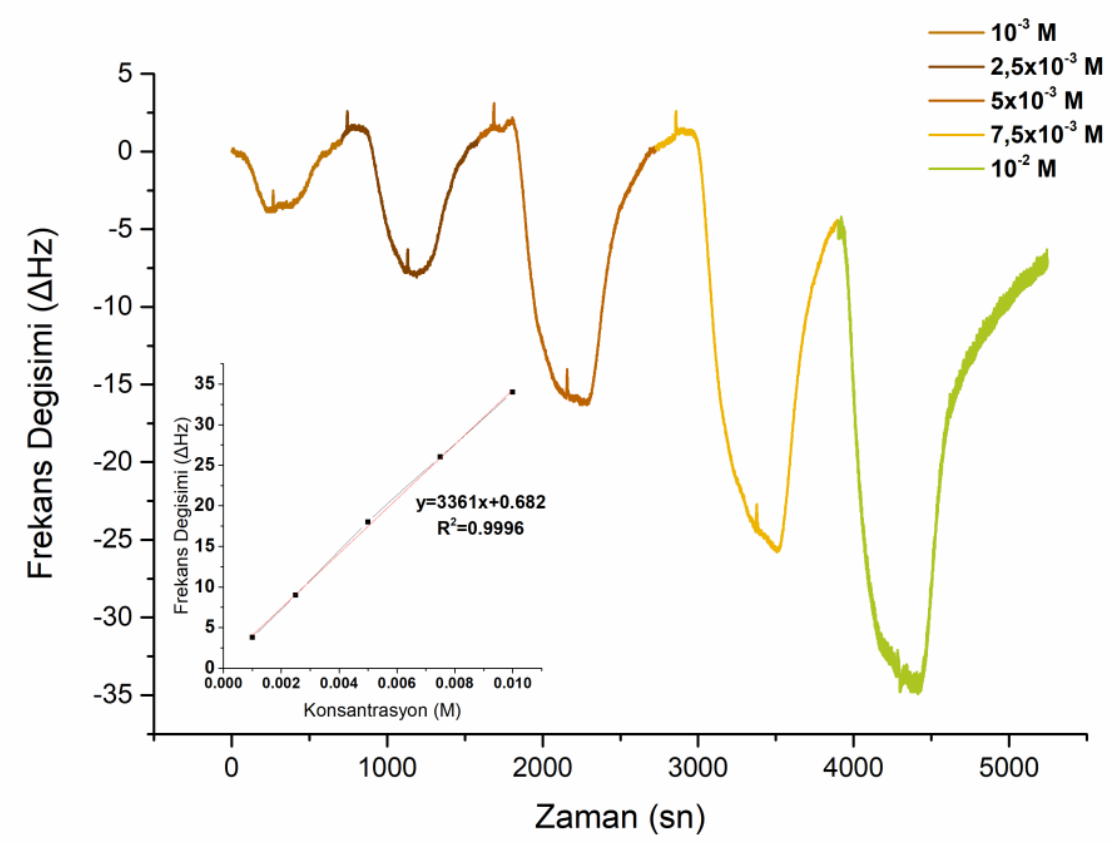

Şekil 5. Farklı konsantrasyonlardaki PNF çözeltilerine karşı KIMR modifiye QCM sensörünün frekans değişimi

Figure 5. Frequency change of KIMR modified QCM sensor towards different concentration of PNF 


\section{pH çalışması (pH study)}

Bilindiği gibi amino grubu içeren maddelerin $\mathrm{pH}^{\prime} \mathrm{a}$ bağlı olarak adsorpsiyon özellikleri değişmektedir (Korpayev ve diğ, 2018). Bu nedenle, algilama sırasında ortamın pH değeri algilama özelliklerini değiştirebilmektedir. Bu nedenle algılama çalışmalarında $\mathrm{pH}$ değerinin etkisi incelenmiştir. Buna göre $\mathrm{pH}$ değeri 2-10 arasında değişen PNF çözeltilerine karşı frekans değişim değerleri Şekil 6’da verilmiştir.

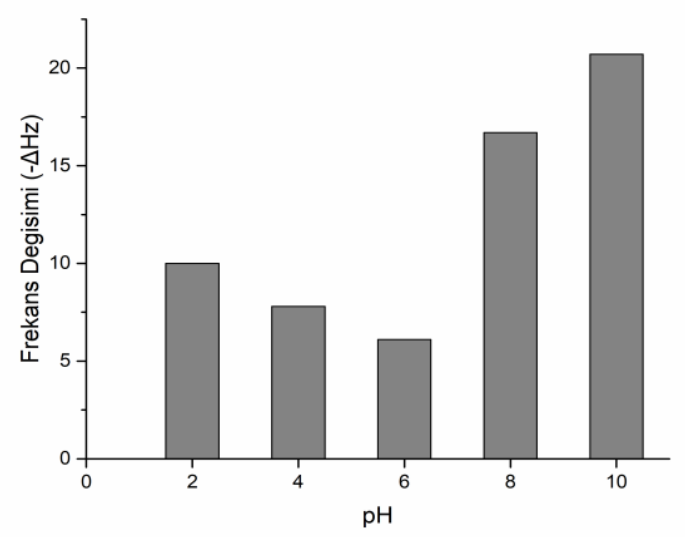

Şekil 6. Farklı pH değerlerindeki PNF çözeltilerine karşı KIMR modifiye QCM sensörünün frekans değişimi

Figure 6. Frequency change of KIMR modified QCM sensor towards PNF solutions at different $p H$

\section{Adsorpsiyon izotermleri (Adsorption isotherms)}

Farklı PNF başlangıç konsantrasyon çalışması sonuçlarından faydalanılarak Langmuir ve Freundlich izotermleri çizilerek Şekil 7 ve 8'de gösterilmiştir. Şekil 7'deki Langmuir izoterminden polimerin adsorpsiyon kapasitesi $\mathrm{q}_{\mathrm{o}}=372 \mathrm{mg} \mathrm{PNF} / \mathrm{g}$ adsorban, $\mathrm{b}=0,013 \mathrm{~L} / \mathrm{mmol}$ olarak hesaplanmıştır. Burada $\mathrm{b}$ değerinin büyük olması, adsorbanın adsorplama yeteneğinin, düşük konsantrasyon aralığında iyi olduğunu göstermektedir. Özellikle tek tabakalı adsorpsiyonun meydana geldiği heterojen adsorpsiyon sistemlerinde bu izoterm denge durumunu net olarak açıklayamaz. Adsorpsiyonun elverişliliğini bulmak için boyutsuz $R_{L}$ (dağılma) sabiti aşağıdaki gibi hesaplanır ve bu sabitin 0 ile 1 arasında değerler alması elverişlilik durumunun sağlandığına işaret eder. Burada RL değerinin 0,883 olarak bulunması adsorpsiyonun Langmuir'e elverişli olduğunu göstermektedir.

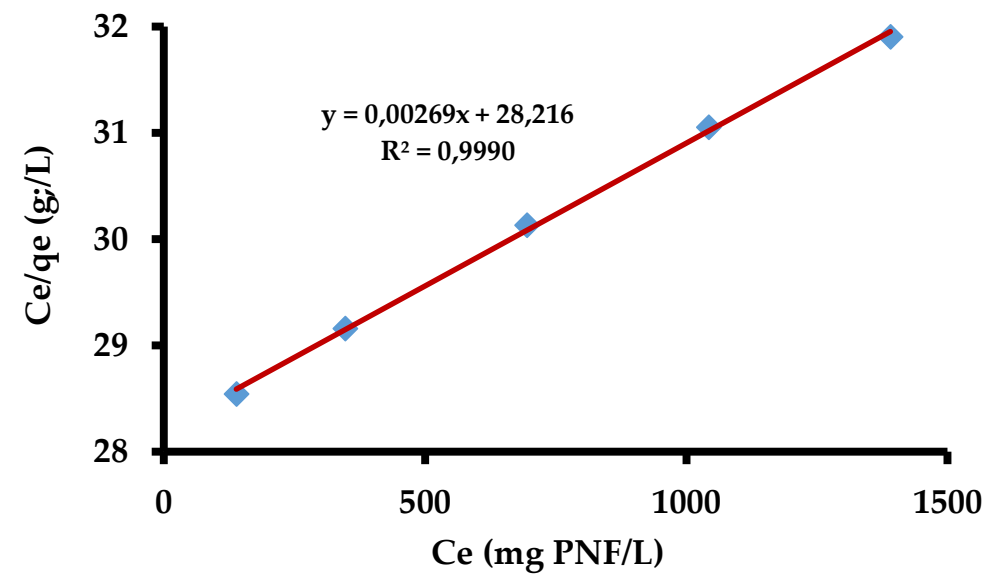

Şekil 7. Langmuir izotermi

Figure 7. Langmuir isotherm 
Şekil 8 'deki Freundlich izoterminden $\mathrm{k}=0,045$ ve $\mathrm{n}=1,05$ olarak hesaplanmıştır. Freundlich izoterminin doğrusallığa yaklaşması, adsorpsiyonun Freundlich izotermine de uyduğunu göstermektedir. Adsorpsiyon izotermlerine ait değerler, Çizelge 1'de verilmiştir.

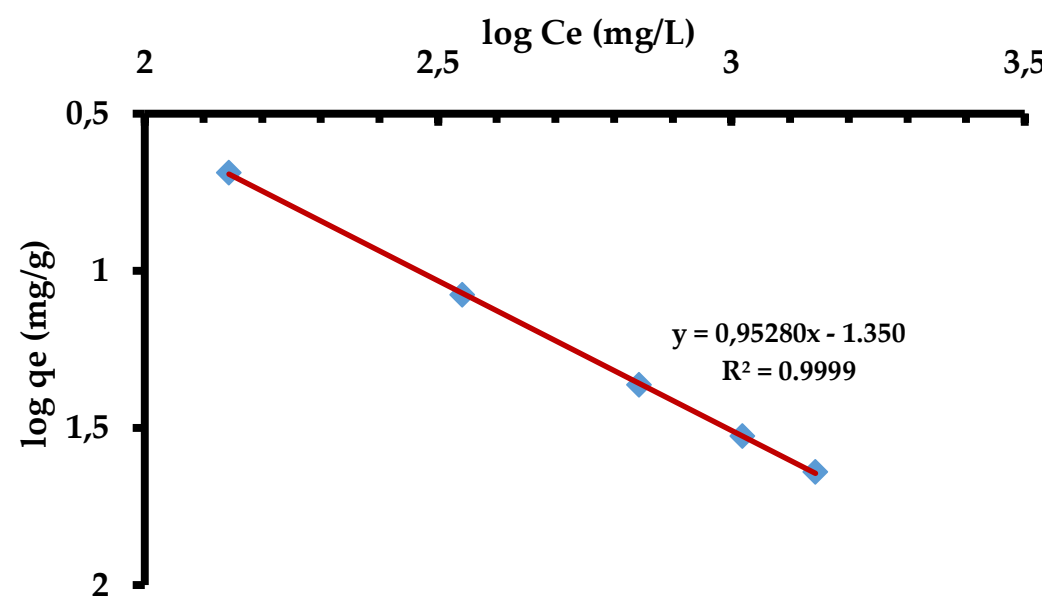

Şekil 8. Freundlich izotermi

Figure 8. Freundlich isotherm

Tablo 1. Langmuir ve Freundlich izoterm model sabitleri ve katsayllar

Table 1. Langmuir and Freundlich isotherm model constants and correlation coefficients

\begin{tabular}{|c|c|c|c|c|c|c|}
\hline \multicolumn{4}{|c|}{ Langmuir } & \multicolumn{3}{|c|}{ Freundlich } \\
\hline $\mathrm{q}_{0}(\mathrm{mg} / \mathrm{g})$ & b $(\mathrm{L} / \mathrm{mmol})$ & $\mathbf{R}^{2}$ & $\mathbf{R}_{\mathbf{L}}$ & $\mathrm{K}_{\mathrm{f}}(\mathrm{mg} / \mathrm{g})$ & n & $\mathbf{R}^{2}$ \\
\hline 372,22 & 0,0132 & 0,9990 & $0<\mathrm{R}_{\mathrm{L}}<1$ & 0,0447 & 1.0495 & 0,9999 \\
\hline
\end{tabular}

\section{SONUÇLAR (CONCLUSIONS)}

$\mathrm{Bu}$ çalışmada; hidrazin amit fonksiyonlu kaliks[4]arenin Merrifield reçinesine immobilize edilmesiyle polimerik yapı (KIMR) hazırlandı ve karakterizasyonu gerçekleştirildi. Daha sonra ise hazırlanan KIMR'nin oldukça toksik olan p-nitrofenol (PNF) kirleticisine karşı adsorpsiyon özellikleri QCM metodu ile belirlendi. Bu amaçla KIMR modifiyeli bir QCM sensör hazırlanarak sulu ortamda PNF'ye karşı algılama özellikleri incelendi. Elde edilen sonuçlardan KIMR modifiyeli sensörün PNF'ye karşı iyi bir algılama gösterdiği, limit algılama değerinin $0,34 \mathrm{mM}$ olduğu ve KIMR adsorpsiyon kapasitesinin $372 \mathrm{mg} / \mathrm{g}$ olduğu belirlendi. Böylece farklı polimerik kaliksaren türevleri hazırlayarak QCM yüzeyine kaplama yönteminin farklı algılama çalışmaları için de gerçekleştirilebileceği sonucuna varılmıştır.

\section{KAYNAKLAR (REFERENCES)}

Collins, E., M., McKervey, M. A., Madigan, E., Moran, M, B., Owens, M., Ferguson, G., Harris, S. J., 1991, "Chemically Modified Calix[4]arenes. Regioselective Synthesis of 1,3-(distal) Derivatives and Related Compounds. X-Ray Crystal Structure of a Diphenol-dinitrile", Journal of the Chemical Society, Perkin Transactions 1, Vol. 12, pp. $3137-3142$.

Dolaksiz, Ekin., Y., Temel, F., Tabakci, M., 2018, "Adsorption of Phenolic Compounds onto Calix[4]arene-bonded Silica Gels from Aqueous Solutions", Reactive and Functional Polymers, Vol. 126, pp. $27-35$. 
Gutsche, C. D., Iqbal, M., 1990, “ p-tert-BUTYLCALIX[4]ARENE”, Organic Syntheses, Vol. 68, pp. 234 237.

Korpayev, S., Kavaklı, C., Tilki, S., Akkaş Kavaklı, P., 2018, “Novel Cotton Fabric Adsorbent for Efficient As(V) Adsorption", Environmental Science and Pollution Research, Vol. 25, pp.34610 - 34622.

Lai,, B., Zhang, Y., Chen, Z., Yang, P., Zhou, Y., Wang, J., 2014, “Removal of p-nitrophenol (PNP) in Aqueous Solution by the Micron-Scale Iron-Copper (Fe/Cu) Bimetallic Particles", Appl Catal B Environ, Vol. 144, pp. $816-830$.

Maity, D., Chakraborty, A., Gunupuru, R., Paul, P., 2011, “Calix[4]arene based Molecular Sensors with Pyrene as Fluoregenic Unit: Effect of Solvent in Ion Selectivity and Colorimetric Detection of Flüoride", Inorganica Chimica Acta, Vol. 372, pp. 126 - 135.

Memon, S., Tabakci, M., Roundhill D. M., Yilmaz, M. 2006, "Synthesis and Evaluation of the Cr(VI) Extraction Ability of Amino/nitrile calix[4]arene Immobilized onto a Polymeric Backbone", Reactive \& Functional Polymer, Vol. 66, pp. 1342 - 1349.

Sauerbrey, G., 1959, "Verwendung von Schwingquarzen zur Wägung dünner Schichten und zur Mikrowägung" Zeitschrift für Physik A Hadrons and Nuclei,. Vol. 155 no.2, pp. 206 - 222.

Temel, F., 2013, Farklı Yapılardaki Kaliksaren Türevlerinin Gaz Algılama Özelliklerinin İncelenmesi, Yüksek Lisans Tezi, Selçuk Üniversitesi, Fen Bilimleri Enstitüsü, Konya.

Temel, F., Ozcelik, E., Ture, A. G., Tabakci, M., 2017, "Sensing Abilities of Functionalized calix[4]arene Coated QCM Sensors Towards Volatile Organic Compounds in Aqueous Media", Applied Surface Science, Vol. 412, pp. $238-251$.

Temel, F., Tabakci, M., 2016, "Calix[4]arene Coated QCM Sensors for Detection of VOC Emission: Methylene Chloride Sensing Studies", Talanta, Vol. 153, pp. 221 - 227.

Yu, P., Huang, K., Zhao, J., Zhang, C., Xie, K., Deng, F., Liu, H. 2010, “A Novel Seperation Technique: Gas-Assisted Three-Liquid-Phase Extraction for Treatment of The Phenolic Wastewater" Sep Purif Technol, Vol. 75, pp. $16-322$. 